\title{
Derivation of Stochastic Equations for Computational Uncertainties in Petro-Physical Properties Using a Simplified Algorithm
}

\section{*'15OFOLABO, O ADEKUNLE; ${ }^{2}$ AMAEFULE JUDE, KEELAN DARE}

\author{
*l Department of Physics, University of Port Harcourt, Rivers State. \\ ${ }^{2}$ *Shell Petroleum Development Company, Port Harcourt, Rivers State \\ adekunle.sofolabo@uniport.edu.ng: aosofolabo@gmail.com.
}

\begin{abstract}
This paper presents a simple mathematical algorithm or procedure for computing the uncertainties at the various percent of data input, using the stochastic approach of simulating the input variables to compute the output variables. A simple algorithm was used to derive stochastic equations for some selected petrophysical parameters using the relative standard deviations techniques $(\sigma)$. These equations also known as reference work equations were found to produce reasonably accepted magnitude of uncertainties in the different parameters associated with cores. Equations were derived for the percent uncertainties in the values of the pore volume of the core $-V_{p}$, the fluid saturation $-S_{w}, S_{o r}$, the porosity of the core $-\Phi$, formation factor $-F$, bulk density $-\rho_{B}$, the derived porosity $-\Phi_{\mathrm{L}}$ and the derived permeability $-\mathrm{K}_{\mathrm{BU}}$, Kro, Krw. The uncertainty equations can also be used to define the maximum level of uncertainty that can be tolerated in any independent variable if the maximum uncertainty to be tolerated in the dependent variable is known. ๑ JASEM

https://dx.doi.org/10.4314/jasem.v21i6.31
\end{abstract}

Keywords: Stochastic equations, petrophysical parameters, percent uncertainties, Mathematical algorithm, standard deviations, partial derivatives, degree of accuracy, empirical models.

\section{LIST OF ABBREVIATION}

\begin{tabular}{|c|c|}
\hline$a=$ & Intercept values of $\mathrm{F}$ at $\mathrm{S}_{\mathrm{w}}=1.0$ \\
\hline$A=$ & Cross sectional area \\
\hline$B_{0}=$ & Oil formation volume factor (res BBL/STB) \\
\hline $\mathrm{CEC}=$ & Cation exchange capacity (milliequivalent/100grams) \\
\hline$\Delta \mathrm{P}_{\mathrm{b}}=$ & Pressure drop (Base permeability) \\
\hline$\Delta \mathrm{P}=$ & Pressure drop \\
\hline $\mathrm{F}=$ & Formation factor $\left(\mathrm{R}_{\mathrm{o}} / \mathrm{R}_{\mathrm{w}}\right)$ \\
\hline$h=$ & Formation thickness (feet) \\
\hline $\mathrm{K}_{\mathrm{L}}=$ & Liquid permeability (Darcies) \\
\hline $\mathrm{K}_{\mathrm{g}}=$ & Gas permeability (Darcies) \\
\hline $\mathrm{K}_{\mathrm{ro}}=$ & Oil relative permeability (fraction) \\
\hline $\mathrm{K}_{\mathrm{rw}}=$ & Water relative permeability (fraction) \\
\hline $\mathrm{K}_{\mathrm{BU}}=$ & Build up permeability (md) \\
\hline $\mathrm{K}_{0}=$ & Oil permeability \\
\hline $\mathrm{L}=$ & length $(\mathrm{cm})$ \\
\hline $\begin{array}{l}\mathrm{m}= \\
\mathrm{n}=\end{array}$ & $\begin{array}{l}\text { Cementation exponent (formation factor equation) } \\
\text { saturation exponent }\end{array}$ \\
\hline $\mathrm{R}_{\mathrm{w}}=$ & Resistivity of saturating brine (ohm-m) \\
\hline $\mathrm{RSD}=$ & Relative Standard Deviation $(\sigma \mathrm{X} / \mathrm{X})$, (fraction) \\
\hline $\mathrm{S}_{\mathrm{w}}=$ & Water saturation (fractional pore volume) \\
\hline $\mathrm{t}_{\mathrm{ma}}=$ & Acoustic travel time of matrix rock (micro $s / f t$ ) \\
\hline$V_{p}=$ & Pore volume (cc) \\
\hline $\mathrm{V}_{\mathrm{G}}=$ & Grain volume (cc) \\
\hline $\mathrm{V}_{\mathrm{mc}}=$ & Matrix cup volume (cc) \\
\hline$V_{o p}=$ & Produced Oil volume (cc) \\
\hline $\mathrm{W}_{\mathrm{l}}=$ & Immersed weight (g) \\
\hline$\Phi=$ & Porosity (fraction) \\
\hline$\rho_{\mathrm{s}}=$ & Saturating fluid density $\left(\mathrm{g} / \mathrm{cm}^{3}\right)$ \\
\hline$\rho_{\mathrm{ma}}=$ & Matrix density $\left(\mathrm{g} / \mathrm{cm}^{3}\right)$ \\
\hline$\rho_{\mathrm{HG}}=$ & Mercury density \\
\hline$\mu_{\mathrm{L}}=$ & Viscosity of Liquid (cp) \\
\hline$\mu_{\mathrm{w}}=$ & Viscosity of water $(\mathrm{cp})$ \\
\hline
\end{tabular}

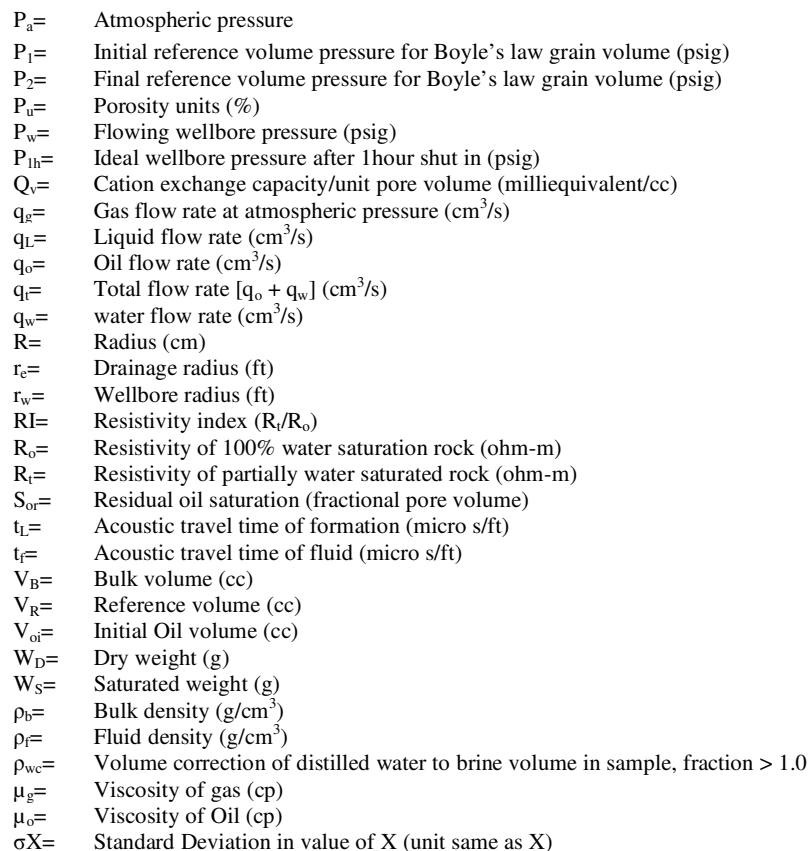

The derivation or computation of petrophysical parameters values is an important step in processing of geological or geophysical data as well as in the interpretation of the subsurface data. Many papers have been presented in respect of the computation or derivation of petrophysical parameters either analytically or by stimulation of models. Determination of the degree of uncertainties associated with the method of computation or derivation of the petrophysical parameters is not a recent development, but determining stochastically the degree of uncertainties in the computed values of the parameters has improved the manners and method of computation. Use of Monte Carlo technique to compute the degree of uncertainties dates back to 1964, when it was used for business decisions (Hertz, 1964). Different authors have used different mathematical models (Stochastically) extensively in analysis, such as in ground water hydrology (Freeze, 1970); (Smith et al., 1979) and for petroleum reservoir simulation (Cekirge et al, 1981); (Smith et al., 1982). A model is said to be stochastic if it contains random variables which have probability distributions, such that the uncertainties in input 
variables are simulated to predict uncertainties in output variables (stochastic approach). Most stochastic models are solved by the Monte Carlo technique, which has been used extensively in quantifying uncertainties in petrophysical deliverables (Bishnu et al., 2005), investigation of errors in relative permeability estimates from the JBN technique (Tao et al., 1984) and to evaluate uncertainties in engineering calculations (Walstrom et al., 1986). Monte Carlo modeling is a flexible technique that allows different interpretation models to be incorporated and the degree of uncertainties computed easily. Given the random variables as a function of normal distribution, then the degree of uncertainty in the expected output variable can be computed or determined empirically from the uncertainties in the random input variables by using the simple algorithm (root mean square equation).

\section{METHODOLOGY}

Stochastical Method: To illustrate the importance of the technique used for computing the uncertainties, a simple mathematical model is derived for some basic petrophysical parameters. Given a petrophysical parameter by a mathematically variable $\mathrm{Y}$ which is proven to be dependent on some independent variables $\mathrm{X}_{\mathrm{i}}:\left(\mathrm{X}_{1}, \mathrm{X}_{2} \ldots \mathrm{X}_{\mathrm{n})}\right.$ and the random error in $\mathrm{Y}$ as $\Delta \mathrm{Y}$. The random error $\Delta \mathrm{Y}$ can be computed from the random errors existing in the independent variables $X_{i}$, if these errors are given as $\Delta X_{1}$, $\Delta \mathrm{X}_{2} \ldots . \Delta \mathrm{X}_{\mathrm{n}}$.

Then, the root mean square error equation can be applies only if the independent variables are not related as:

and

$$
Y=f\left(X_{1}, X_{2}, X_{3}, \ldots \ldots \ldots \ldots \ldots \ldots \ldots X_{n}\right) \quad 1
$$

$$
\Delta \mathrm{Y}= \pm\left[\left(\frac{\delta \mathrm{Y}}{\delta \mathrm{X}_{1}} \Delta \mathrm{X}_{1}\right)^{2}+\left(\frac{\delta \mathrm{Y}}{\delta \mathrm{X}_{2}} \Delta \mathrm{X}_{2}\right)^{2}+\left(\frac{\delta \mathrm{Y}}{\delta \mathrm{X}_{3}} \Delta \mathrm{X}_{3}\right)\right]^{1 / 2} 2
$$

The technique or method for determining the level of uncertainty was previously applied to selected core measurements by Hook (1983) and also applied to water saturations calculated from the Waxman-Smits equation by Freedman et al (1985) and in the analysis of the Archie equation components by Chen et al (1986).

The random errors in many different physical processes can be approximated by a normal distribution, thus the errors are probabilistic in nature, hence stochastic in approach. For the above errors values, errors $\Delta \mathrm{X}_{1}, \Delta \mathrm{X}_{2}, \ldots \ldots \Delta \mathrm{X}_{\mathrm{n}}$ and $\Delta \mathrm{Y}$ can be represented by the standard deviations of the values as $\sigma \mathrm{X}_{1}, \sigma \mathrm{X}_{2}, \ldots \ldots \sigma \mathrm{X}_{\mathrm{n}}$ and $\sigma \mathrm{Y}$ respectively.

Thus using a simple stochastic technique for the above equations, the following simple algorithms (steps) are derived and used:

1. Deriving an equation relating the dependent variable $\mathrm{Y}$ to its independent variables $\mathrm{X}$, i.e

$$
\mathrm{F}=\frac{\mathrm{R}_{\mathrm{o}}}{\mathrm{R}_{\mathrm{w}}}
$$

2. Next compute the partial derivatives of the parameters:

$$
\frac{\delta Y}{\delta X} \text { i.e..., } \frac{\delta F}{\delta R_{o}} \text { and } \frac{\delta F}{\delta R_{W}}
$$

Substituting the partial derivatives (Equation 3 and 4) into the derived error equation given in equation 2 above, and manipulating the resulting equation to usable form, we derive

$$
\begin{aligned}
& \sigma F= \pm F\left[\left(\frac{\sigma R_{O}}{R_{O}}\right)^{2}+\left(\frac{\sigma R_{W}}{R_{W}}\right)^{2}\right]^{1 / 2} \\
& \frac{\sigma F}{F}= \pm\left[\left(\frac{\sigma R_{O}}{R_{O}}\right)^{2}+\left(\frac{\sigma R_{W}}{R_{W}}\right)^{2}\right]^{1 / 2} 6
\end{aligned}
$$

In equation 5 and 6 , the ratio of the standard deviation $(\sigma \mathrm{F})$ to the value of the variable $(\mathrm{F})$ is referred to as the relative standard deviation $(\sigma F / F)$ and this is commonly computed in fraction or percent.

Finally, derive the degree or level of the parameter uncertainty $\left(\sigma \mathrm{R}_{0} / \mathrm{R}_{0}\right)$ and $\sigma \mathrm{R}_{\mathrm{w}} / \mathrm{R}_{\mathrm{w}}$ in the parameter and calculate the resultant relative standard deviation of the dependent variable $(\sigma \mathrm{F} / \mathrm{F})$. If the uncertainty in a given case is expressed as the relative standard deviation with units of fraction or percent (i.e., $\sigma \mathrm{R}_{0} / \mathrm{R}_{0}$ ), no actual values of $\mathrm{R}_{0}$ is necessary required to solve the equations. But in some cases the numerical values must be assigned (This technique or approach is used in deriving the uncertainty level of the parameters), such as in the calculation of pore volume by difference of bulk volume $\left(\mathrm{V}_{\mathrm{B}}\right)$ and grain volume $\left(\mathrm{V}_{\mathrm{G}}\right)$, where numeric values of $\mathrm{V}_{\mathrm{B}}$ and $\mathrm{V}_{\mathrm{G}}$ is assigned. In deriving the equation for uncertainty level of some petrophysical parameters, the independent variables and the equations commonly used to determine core data basic properties such as pore volume, bulk volume, grain volume and porosity are shown in Table 1 (Amaefule, 1989). Similar data relating to core residual oil saturation, electrical properties and specific and relative permeability are also shown in the table as well as variables for well test data and log derived properties. Partial derivatives for the parameters were determined for each independent variable, and the resultant uncertainty equations derived as shown for some selected variable in Table 2, these equations are also known as

Reference Work Equations: These equations allows for insertion of any standard deviation or relative standard deviation desired into the uncertainty equation for subsequent calculation of uncertainty of the computed variable. For example, insertion of the percentage uncertainty in $R_{0}$, which is represented by $\left(\sigma \mathrm{R}_{0} / \mathrm{R}_{0}\right)$, and the percentage uncertainty in $\mathrm{R}_{\mathrm{w}}$, which 
is represented by $\left(\sigma \mathrm{R}_{\mathrm{w}} / \mathrm{R}_{\mathrm{w}}\right)$ allows for the calculation $\quad(\sigma \mathrm{F} / \mathrm{F})$ as shown in Table 2 (Amaefule, 1989). of the percentage uncertainty in $\mathrm{F}$, represented by

Table 1: Core Data Computed Variables, Independent Variables and Models Equations (Amaefule, 1989)

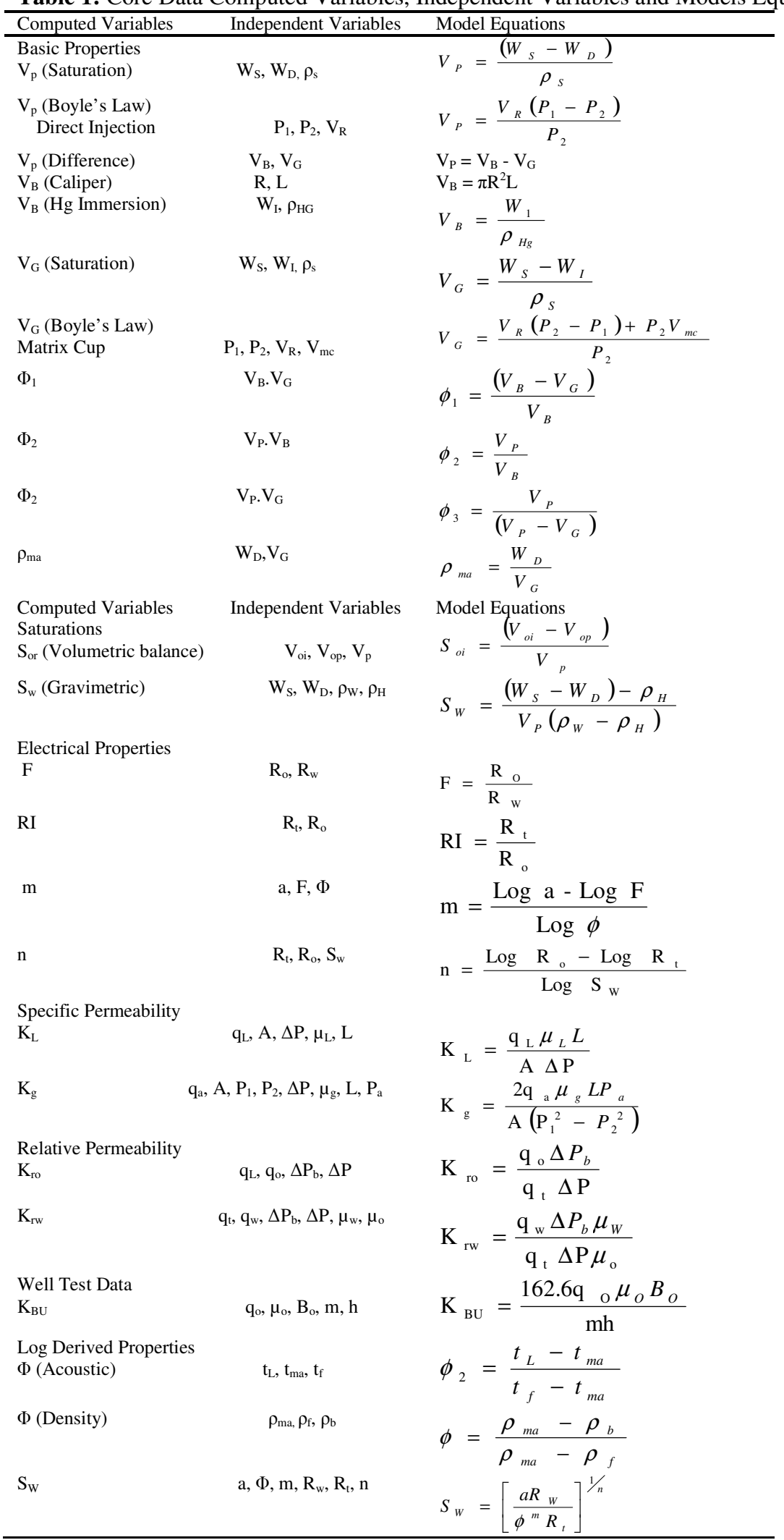


Table 2: Derived Uncertainties Equations for Some Selected Petrophysical Properties (Core Data) (Amaefule, 1989):

\begin{tabular}{l} 
Computed Variables \\
\hline 1. Basics Properties
\end{tabular}

- Pore Volume $\left(V_{p}\right)$

$\mathrm{V}_{\mathrm{P}}$ (saturation)

$\mathrm{V}_{\mathrm{P}}$ (Boyle's Law)

$\mathrm{V}_{\mathrm{P}}($ Difference $)$

$$
\frac{{ }^{\sigma} \mathrm{V}_{\mathrm{P}}}{\mathrm{V}_{\mathrm{P}}}= \pm\left[\left(\frac{{ }^{\sigma} W_{S}}{W_{S}-W_{D}}\right)^{2}+\left(\frac{{ }^{\sigma} W_{D}}{W_{S}-W_{D}}\right)^{2}+\left(\frac{{ }^{\sigma} \rho_{S}}{\rho_{S}}\right)^{2}\right]^{1 / 2}
$$

- Bulk Volume $\left(V_{B}\right)$

$$
\begin{aligned}
& \frac{{ }^{\sigma} \mathrm{V}_{\mathrm{P}}}{\mathrm{V}_{\mathrm{P}}}= \pm\left[\left(\frac{{ }^{\sigma} V_{R}}{V_{R}}\right)^{2}+\left\{\left(\frac{{ }^{\sigma} P_{2}}{P_{2}}\right)\left(\frac{P_{1}}{P_{1}-P_{2}}\right)\right\}^{2}+\left(\frac{{ }^{\sigma} P_{1}}{P_{1}-P_{2}}\right)^{2}\right]^{1 / 2} \\
& \frac{{ }^{\sigma} \mathrm{V}_{\mathrm{P}}}{\mathrm{V}_{\mathrm{P}}}= \pm\left[\left(\frac{{ }^{\sigma} V_{B}}{V_{B}-V_{G}}\right)^{2}+\left(\frac{{ }^{\sigma} V_{G}}{V_{B}-V_{G}}\right)^{2}\right]^{1 / 2}
\end{aligned}
$$

$\mathrm{V}_{\mathrm{B}}$ (Caliper)

$\mathrm{V}_{\mathrm{B}}(\mathrm{Hg}$ Immersion $)$

$$
\frac{{ }^{\sigma} \mathrm{V}_{\mathrm{B}}}{\mathrm{V}_{\mathrm{B}}}= \pm\left[\left(\frac{{ }^{2 \sigma} R}{R}\right)^{2}+\left(\frac{{ }^{\sigma} L}{L}\right)^{2}\right]^{1 / 2}
$$

Grain Volume $\left(V_{G}\right)$

$$
\frac{{ }^{\sigma} \mathrm{V}_{\mathrm{B}}}{\mathrm{V}_{\mathrm{B}}}= \pm\left[\left(\frac{{ }^{\sigma} W_{1}}{W_{1}}\right)^{2}+\left(\frac{{ }^{\sigma} \rho_{H g}}{\rho_{H g}}\right)^{2}\right]^{1 / 2}
$$

$\mathrm{V}_{\mathrm{G}}$ (Saturation)

$$
\frac{{ }^{\sigma} \mathrm{V}_{\mathrm{G}}}{\mathrm{V}_{\mathrm{G}}}= \pm\left[\left(\frac{{ }^{\sigma} W_{S}}{W_{S}-W_{1}}\right)^{2}+\left(\frac{{ }^{\sigma} W_{1}}{W_{S}-W_{1}}\right)^{2}+\left(\frac{{ }^{\sigma} \rho_{S}}{\rho_{S}}\right)^{2}\right]^{1 / 2}
$$

Porosity $(\Phi)$

$\Phi_{1}$

$$
\frac{{ }^{\sigma} \phi_{1}}{\phi_{1}}= \pm \frac{V_{G}}{V_{B}-V_{G}}\left[\left(\frac{{ }^{\sigma} V_{G}}{V_{G}}\right)^{2}+\left(\frac{{ }^{\sigma} V_{B}}{V_{B}}\right)^{2}\right]^{1 / 2}
$$

$\Phi_{2}$

$$
\frac{{ }^{\sigma} \phi_{2}}{\phi_{2}}= \pm\left[\left(\frac{{ }^{\sigma} V_{P}}{V_{P}}\right)^{2}+\left(\frac{{ }^{\sigma} V_{B}}{V_{B}}\right)^{2}\right]^{1 / 2}
$$

Matrix Density $(\rho)$

$\rho_{\text {ma }}$

$$
\frac{{ }^{\sigma} \rho_{m a}}{\rho_{m a}}= \pm\left[\left(\frac{{ }^{\sigma} W_{D}}{W_{D}}\right)^{2}+\left(\frac{{ }^{\sigma} V_{G}}{V_{G}}\right)^{2}\right]^{1 / 2}
$$

2. Saturations

$\mathrm{S}_{\text {or }}$ (Volumetric Balance)

$$
\frac{{ }^{\sigma} S_{o r}}{S_{o r}}= \pm\left[\left(\frac{{ }^{\sigma} V_{P}}{V_{P}}\right)^{2}+\left\{\left(\frac{{ }^{\sigma} V_{o i}}{V_{o i}}\right)\left(\frac{V_{o i}}{V_{o i}-V_{o p}}\right)\right\}^{2}+\ldots . .+\left\{\left(\frac{{ }^{\sigma} V_{o p}}{V_{o p}}\right)\left(\frac{V_{o p}}{V_{o i}-V_{o p}}\right)\right\}^{2}\right.
$$

3. Electrical Properties

- F (formation factor)

RI (Resistivity Index) -

$$
\left(\mathrm{R}_{\mathrm{t}} / \mathrm{R}_{\mathrm{o}}\right)
$$

$-\mathrm{m}$ (Cementation exponent)

$$
\begin{aligned}
& \frac{{ }^{\sigma} F}{F}= \pm\left[\left(\frac{{ }^{\sigma} R_{O}}{R_{O}}\right)^{2}+\left(\frac{{ }^{\sigma} R_{W}}{R_{W}}\right)^{2}\right]^{1 / 2} \\
& \frac{{ }^{\sigma} R I}{R I}= \pm\left[\left(\frac{{ }^{\sigma} R_{t}}{R_{t}}\right)^{2}+\left(\frac{{ }^{\sigma} R_{o}}{R_{o}}\right)^{2}\right]^{1 / 2}\left[\frac { 1 } { \operatorname { l n } ( \frac { a } { f } ) } \left[\left(\frac{\sigma a}{a}\right)^{2}+\left(\frac{\sigma^{\sigma} F}{F}\right)^{2}+\ldots \ldots \ldots . . . . .+\left(\frac{\ln \left(\frac{a}{f}\right)}{\ln \phi} \cdot \frac{\sigma_{\phi}}{\phi}\right)^{2}\right.\right. \\
& \frac{{ }^{\sigma} m}{m}= \pm
\end{aligned}
$$$$
\text { - n (Saturation exponent) }
$$ 


$$
\frac{{ }^{\sigma} n}{n}= \pm\left[\left(\frac{{ }^{\sigma} S_{W}}{S_{W}} \cdot \frac{1}{\ln S_{W}}\right)^{2}+\left(\frac{{ }^{\sigma} R_{t}}{R_{t}} \cdot \frac{1}{\ln \left(R_{t} / R_{o}\right)}\right)^{2}+\ldots \ldots \ldots \ldots . . . .+\left(\frac{{ }^{\sigma} R_{o}}{R_{o}} \bullet \frac{1}{\ln \left(R_{t} / R_{o}\right)}\right)^{2}\right]^{1}
$$

4.Specific Permeability

$\mathrm{K}_{\mathrm{L}}$ ( Liquid Permeability)

Note:

$$
\begin{gathered}
{ }^{\sigma} \ln K_{L} \cong \pm\left[\left(\frac{{ }^{\sigma} q_{L}}{q_{L}}\right)^{2}+\left(\frac{{ }^{\sigma} A_{L}}{A}\right)^{2}+\left(\frac{{ }^{\sigma} \Delta P}{d P}\right)^{2}+\left(\frac{{ }^{\sigma} \mu_{L}}{\mu_{L}}\right)^{2}+\ldots+\left(\frac{{ }^{\sigma} L}{L}\right)^{2}\right. \\
\frac{{ }^{\sigma} K_{L}}{K_{L}} \cong\left[\left(\ell^{ \pm \sigma} \ln K_{L}\right)-1\right]
\end{gathered}
$$

5.Relative Permeability

$\mathrm{K}_{\mathrm{ro}}$ (Oil relative

Permeability

$$
\frac{{ }^{\sigma} K_{r o}}{K_{r o}}= \pm\left[\left(\frac{{ }^{\sigma} q_{t}}{q_{t}}\right)^{2}+\left(\frac{{ }^{\sigma} q_{o}}{q_{o}}\right)^{2}+\left(\frac{{ }^{\sigma} \Delta P_{b}}{\Delta P_{b}}\right)^{2}+\left(\frac{{ }^{\sigma} \Delta P}{\Delta P}\right)^{2}\right]
$$

\section{Well Test Data}

$\mathrm{K}_{\mathrm{BU}}$ (Build-up

Permeability)

Note:

$$
\begin{aligned}
{ }^{\sigma} \ln K_{B U} \cong \pm\left[\left(\frac{{ }^{\sigma} q_{o}}{q_{o}}\right)^{2}+\left(\frac{{ }^{\sigma} \mu_{o}}{\mu_{o}}\right)^{2}+\left(\frac{{ }^{\sigma} B_{o}}{B_{o}}\right)^{2}+\ldots \ldots \ldots . . .+\left(\frac{{ }^{\sigma} m}{m}\right)+\left(\frac{{ }^{\sigma} h}{h}\right)^{2}\right. \\
\frac{{ }^{\sigma} K_{B U}}{K_{B U}} \cong\left[\left(\ell^{ \pm \sigma} \ln K_{B U}\right)-1\right]
\end{aligned}
$$

7. Log Derived Properties

$\Phi$ (Acoustic)

$$
\frac{{ }^{\sigma} \phi}{\phi}= \pm\left[\begin{array}{l}
\left\{\left(\frac{{ }^{\sigma} t_{L}}{t_{L}}\right)\left(\frac{t_{L}}{t_{L}-t_{m a}}\right)\right\}^{2}+\left\{\left(\frac{{ }^{\sigma} t_{f}}{t_{f}}\right)\left(\frac{t_{f}}{t_{f}-t_{m a}}\right)\right\}^{2}\left(\frac{{ }^{\sigma} t_{L}}{t_{L}}\right)^{2}+\ldots . . . \\
\ldots \ldots \ldots \ldots \ldots . . .+\left\{\left(\frac{{ }^{\sigma} t_{m a}}{t_{m a}}\right)\left(\frac{t_{m a}}{t_{f}-t_{m a}}\right)\left(\frac{t_{L}-t_{f}}{t_{f}-t_{m a}}\right)\right\}^{2}
\end{array}\right.
$$

$\mathrm{S}_{\mathrm{w}}$ (Water Saturation fractional pore volume)

$$
\frac{{ }^{\sigma} S_{W}}{S_{W}}= \pm \frac{1}{n}\left[\begin{array}{l}
\left(\frac{{ }^{\sigma} a}{a}\right)^{2}+\left(\frac{{ }^{\sigma} R_{W}}{R_{W}}\right)^{2}+\left(\frac{{ }^{\sigma} R_{t}}{R_{t}}\right)^{2}+\ldots \ldots \ldots \ldots \ldots . . . . . . . . . . . . .+m^{2}\left(\frac{{ }^{\sigma} \phi}{\phi}\right)^{2}+(m-\ln \phi)^{2}\left(\frac{{ }^{\sigma} m}{m}\right)^{2}+\ldots .+\left(n * \ln S_{W}\right)^{2}\left(\frac{{ }^{\sigma} n}{n}\right)^{2} \\
\ldots \ldots \ldots \ldots . .
\end{array}\right.
$$

\section{RESULTS AND DISCUSSION}

Derivation of Uncertainty Equation Of Selected Petro physical Parameters: Stochastic technique is used to derive equations for some selected petrophysical parameters using the relative standard deviation equations obtained and the root mean square technique. Some of the derived equations shown in Table 2, are used in various ways, the uncertainty assigned can be of equal or unequal value depending on each of the independent variables. Experimentally, some of the variables are less rigidly controlled with large standard deviations, from the mean value or technique limitations derived values that vary within larger percentages than others. The differences in values are accounted for in the uncertainty equations, which will give an appropriate uncertainty values in the computed variables. Examples of the derivation of stochastic equations using the simple algorithm and the parameters in Table 2 are:

Pore Volume: The equation for calculating the percent uncertainty in pore volume $\mathrm{Vp}$ resulting for uncertainty in core dry weight, saturated weight and density of saturated fluid is given as 


$$
\begin{aligned}
& V_{P}=\frac{\left(W_{S}-W_{D}\right)}{\rho_{S}} \\
& \frac{{ }^{\sigma} \mathrm{V}_{\mathrm{P}}}{\mathrm{V}_{\mathrm{P}}}= \pm\left[\left(\frac{{ }^{\sigma} W_{S}}{W_{S}-W_{D}}\right)^{2}+\left(\frac{{ }^{\sigma} W_{D}}{W_{S}-W_{D}}\right)^{2}+\left(\frac{{ }^{\sigma} \rho_{S}}{\rho_{S}}\right)^{2}\right]^{1 / 2} \\
& \frac{{ }^{\sigma} \mathrm{V}_{\mathrm{P}}}{\mathrm{V}_{\mathrm{P}}}= \pm\left[\left(\frac{\sigma W_{S}}{W_{S}} \cdot \frac{W_{S}}{W_{S}-W_{D}}\right)^{2}+\left(\frac{{ }^{\sigma} W_{D}}{W_{D}} \cdot \frac{W_{D}}{W_{S}-W_{D}}\right)^{2}+\left(\frac{{ }^{\sigma} \rho_{S}}{\rho_{S}}\right)^{2}\right]^{1 / 2}
\end{aligned}
$$

Porosity: The equation for calculating the percent uncertainty $\left(\frac{{ }^{\sigma} \phi}{\phi}\right)$ in porosity resulting from uncertainty in core bulk and grain volumes is given as

$$
\begin{aligned}
& \phi=\frac{\mathrm{V}_{\mathrm{B}}-V_{G}}{\mathrm{~V}_{\mathrm{B}}} \\
& \frac{{ }^{\sigma} \phi}{\phi}= \pm \frac{V_{G}}{V_{B}-V_{G}}\left[\left(\frac{{ }^{\sigma} V_{G}}{V_{G}}\right)^{2}+\left(\frac{{ }^{\sigma} V_{B}}{V_{B}}\right)^{2}\right]^{1 / 2}
\end{aligned}
$$

Formation Factor: The equation for calculating the percent uncertainty $\left(\frac{\sigma F}{F}\right)$ in formation factor $(\mathrm{F})$ for uncertainty in resistivity of $100 \%$ saturated sample resistivity $R_{o}$ and water resistivity $R_{w}$ is given as

$$
\begin{aligned}
& \mathrm{F}=\frac{\mathrm{R}_{O}}{\mathrm{R}_{\mathrm{w}}} \\
& \frac{\sigma F}{F}= \pm\left[\left(\frac{\sigma R_{O}}{R_{O}}\right)^{2}+\left(\frac{\sigma R_{W}}{R_{W}}\right)^{2}\right]^{1 / 2} .
\end{aligned}
$$

Permeability: The equation for calculating the percent uncertainty $\frac{\sigma K_{B U}}{K_{B U}}$ in well build-up permeability for uncertainty in flow rate, viscosity, formation volume factor, slope and thickness is given as

$$
\begin{aligned}
\ln K_{B U} & =\ln \left(\frac{162.6 q_{o} \mu_{o} B_{o}}{m h}\right) \\
{ }^{\sigma} \ln K_{B U} & =\ln \left(\frac{{ }^{\sigma} q_{o}}{q_{o}}\right)^{2}+\left(\frac{{ }^{\sigma} \mu_{o}}{\mu_{o}}\right)^{2}+\left(\frac{{ }^{\sigma} B_{o}}{B_{o}}\right)^{2}+\left(\frac{{ }^{\sigma} m}{m}\right)^{2}+\left(\frac{{ }^{\sigma} h}{h}\right)^{2}
\end{aligned}
$$

The derived stochastic equations makes its easy and simple to determine the degree of uncertainties of any petrophysical parameters, these equations can easily be verified with derived or experimentally petrophysical parameters values .

Conclusions: A generalized uncertainty equation utilizing the root mean square equation has been developed for some selected laboratory core measurements, well and log data parameters. These equations can be used to compute the degree or percent uncertainty of each independent variable to the total uncertainty of the dependent variable, this procedure assist in identifying the independent variables contributing most to the uncertainty level and the parameters to target for reduction in the degree of uncertainty of the parameters or uncertainty effects. These uncertainty equations are generic solutions, this allows for uncertainty opportunity or environs that allows for dependent variables for any assigned value of uncertainty in the independent variables.

High correlation between the observed and calculated uncertainty for laboratory derived porosity and formation factor support the equations used to theoretically assess uncertainty in a dependent variable when reasonable values of uncertainty in the independent variables are assigned. The uncertainty equations can also be used to define the maximum level of uncertainty that can be tolerated in any independent variable if the maximum uncertainty to be tolerated in the dependent variable is known. 


\section{REFERENCES}

Amaefule, J.O (1989)."Stochastic approach in Uncertainties computation”. Society of core Analysts, SCA 8907

Adams S.J. (2005).“Quantifying Petrophysical Uncertainties”. SPE 93125

Akins, W.M., Abell, M.P. (2005). "Enhancing Drilling Risk \& Performance Management Through the Use of Probabilistic Time \& Cost Estimating”, SPE, 92340

Bishnu, K., Varghese, J (2005), “Application of Monte Carlo Stimulation to Quantify Uncertainties in Petrophysical Delivarables". Schlumberger Information Solutions, India, Geohorizons

Cekirge, H.M., Kleppe, J., Lehr, W.J. (1981). "Stochastic methods in Reservoir Engineering": SPE Middle East Oil Technical Conference, Bahrain (SPE 9608).

Chen, H.C., Fang, J.H. (1986). "Sensitivity Analysis of Parameters on Archie's Water Saturation Equation'": The Log Analyst, Parameters, Soc. of Core Analysts, No. SCA-8907Sep-Oct, pp 39-44.

Freeze, R. A, (1975), “A Stochastic Conceptual analysis of One Dimensional Ground water flow in Non-Uniform Homogeneous Media': American Geophysical Union Publication, Vol. 2, No 5, pp 725-741.

Hertz, D.B. (1964): Risk Analysis in Capital Investment, Harvard Business Review, 42, No.1, p. $95-106$

Freedman, R., Ausburn, B.E. (1985). “The WaxmanSmits Equation for Shaly Sands: Simple Methods of Solution, Error Analysis'': The Log Analyst, March-April, pp11-24.

Hook, J. R, (1983). "The Precision of Core Analysis Data and Some Implication for Reservoir Evaluation'": SPWLA 28 ${ }^{\text {th }}$ Annual Logging Symposium, June.
Hooper H.T.(2001). "Probabilistic prospect evaluation with spreadsheets", SPE, 68594

Komlosi, Z. P. (2001). "Application: Monte Carlo Simulation in Risk Evaluation of E\&P Projects", SPE, 68578

Nakayama, K. (2000). "Estimation of Reservoir Properties by Monte Carlo Simulation", SPE, 59408

Reed, R. L. (1972). “A Monte Carlo Approach to Optimal Drilling”, SPE, 3513

Smith, L., Freeze, R.A. (1979). "Stochastic Analysis of Steady State Groundwater Flow in a Bounded Domain: One-Dimensional Simulations-Part 1': American Geophysical Union Publication, Vol. 15, No 3, June, pp 1521-1528

Smith, L., Freeze, R.A. (1979). "Stochastic Analysis of Steady State Groundwater Flow in a Bounded Domain: Two-Dimensional Simulations-Part 2', American Geophysical Union Publication, Vol. 15, No 6, December, pp 1543-1559.

Smith, J.S., Brown, C.E. (1982). "Stochastic Modeling of Two-Phase Flow In Porous Media"; $57^{\text {th }}$ Annual Fall Technical Conference of SPE, New Orleans, Louisiana September, SPE 11128.

Qinshan, Y., Torres-Verdin, C (2013): “Joint Stochastic Interpretation of Conventional Well Logs acquired in Hydrocarbon bearing Shale". Society of Petrophysical and Well Log Analysis (SPWLA), 54 ${ }^{\text {th }}$ Annual Logging Symposium, pp $1-15$

Tao, T.M., Watson, A.T. (1984). “Accuracy of JBN estimates of relative Permeability - Error analysis": SPE Journal, April, pp 209-223.

Walstrom, J.E., Mueller, T.D., McFarlane, R.C. (1986). "Evaluating Uncertainty in Engineering Calculations": Journal of Petroleum Technology, December, pp 1595-1603.

Interactive Petrophysics-TM: A PC based Advanced Log analysis software that has been developed by Production Geoscience Ltd. and worldwide sales and product support is being provided by Schlumberger Information Solutions. 